DR FILOMENA GIULIA SILEO (Orcid ID : 0000-0001-7380-0576)

DR AMAR BHIDE (Orcid ID : 0000-0003-2393-7501)

Article type : Systematic review

\title{
Perinatal outcomes of twin pregnancies affected by early twin-twin transfusion syndrome: a systematic review and meta-analysis
}

Francesco D'ANTONIO ${ }^{1}$, Can Benlioglu ${ }^{2}$, Filomena Giulia SILEO ${ }^{2,3}$, Basky

THILAGANATHAN, Aris PAPAGEORGHIOU, Amarnath BHIDE ${ }^{2}$, Asma KHALIL ${ }^{2,4}$

${ }^{1}$ Department of Obstetrics and Gynecology, Department of Medical and Surgical Sciences, University of Foggia, Foggia, Italy

${ }^{2}$ Fetal Medicine Unit, St George's Hospital, St George's University of London, London, UK.

${ }^{3}$ Prenatal Medicine Unit, Obstetrics and Gynecology Unit, Department of Medical and Surgical

Sciences for Mother, Child and Adult, University of Modena and Reggio Emilia, Modena, Italy ${ }^{4}$ Vascular Biology Research Centre, Molecular and Clinical Sciences Research Institute, St

George's University of London, London, UK.

\section{Corresponding Author:}

Asma Khalil

Fetal Medicine Unit, Department of Obstetrics and Gynaecology, St. George's University

Hospitals NHS Foundation Trust, Blackshaw Road, London, SW17 0QT, UK.

E-mail: akhalil@sgul.ac.uk

\section{Conflict of interests:}

\section{None}

This article has been accepted for publication and undergone full peer review but has not been through the copyediting, typesetting, pagination and proofreading process, which may lead to differences between this version and the Version of Record. Please cite this article as doi: 10.1111/AOGS.13840

This article is protected by copyright. All rights reserved 


\section{ABSTRACT}

Introduction: Twin-to-twin transfusion syndrome (TTTS) is associated with a high risk of perinatal mortality and morbidity if not treated. However, the optimal timing and management in case of early (occurring $<18$ weeks) TTTS has not been established yet. Material and Methods: This is a systematic review and meta-analysis aiming at evaluating the outcomes of monochorionic diamniotic (MCDA) twin pregnancies complicated by early (i.e. before 18 weeks) TTTS according to different management options (expectant, laser therapy, amnioreduction or cord occlusion). The primary outcome was mortality, including single and double intra-uterine, neonatal and perinatal death. Secondary outcomes were: composite morbidity, neuromorbidity, respiratory distress syndrome, admission to neonatal intensive care unit, intact survival (defined as survival free from neurological complications) and preterm birth $<32$ weeks' gestation. All outcomes were reviewed according to the different management options (expectant, laser therapy, amnioreduction or cord occlusion) and reported in the overall population of twins, and in the donor and recipient separately. Sub-group analysis for TTTS occurring before 16 weeks of gestation was performed. Random-effect meta-analyses of proportions were used to analyze the data. Results: Thirteen studies were included. Early TTTS occurred in 14.3\% (95\% CI 11.9-17.0) of cases. Mortality: The incidence of intra-uterine death was $19.0 \%$ (95\% CI 2.6-45.5) in twins managed expectantly, $32.4 \%$ (95\% CI 16.5-50.7) in those who received laser treatment and $12.5 \%$ (95\% CI 4.8-23.0) in those treated with amnioreduction. The incidence of neonatal death was $22.6 \%$ (95\% CI 4.2-49.8) in twins managed expectantly, 24.7\% (95\% CI 0.5-80.3) in those who received laser and 20.2 (95\% CI 5.8-43.4) in those who had amnioreduction, while it was not possible to compute the incidence of these outcomes in twins undergoing cord occlusion because of insufficient sample and lack of reporting of most of the observed outcomes. Overall, the incidence of perinatal death was $43.9 \%$ (95\% CI 5.9-87.7) in twins managed expectantly, $47.3 \%$ (95\% CI 21.4-70.) in those treated with laser and $28.5 \%$ in those who had amnioreduction.

Conclusions: Twin pregnancies affected by early TTTS are at substantial risk of perinatal mortality and morbidity; however data comes from very small studies with high risk of selection bias.

Key words: twins; monochorionic; twin-twin transfusion syndrome; cord occlusion; laser; metaanalysis; systematic review; 


\section{List of abbreviations:}

CI: confidence interval;

IUD: intra-uterine death;

MCDA: monochorionic diamniotic;

NOS: Newcastle-Ottawa Scale;

PND: perinatal death;

PTB: preterm birth;

TTTS: twin-to-twin transfusion syndrome

\section{Key Message:}

Perinatal mortality and morbidity are a substantial risk for twin pregnancies complicated by early TTTS identified from small studies. There is a need for comprehensive reporting of outcome data using standardized format and multicentre undertaking. 


\section{INTRODUCTION}

Twin-to-twin transfusion syndrome (TTTS) is one of the most severe complications of monochorionic diamniotic (MCDA) twin pregnancies, with an estimated incidence of $10-15 \%$ (1). Although its pathophysiology has not been fully elucidated yet, the initial process that triggers TTTS is thought to result from unbalanced flow across the placental inter-twin vascular anastomoses, causing relative hypovolemia in one twin and hypervolemia in the other $(2,3)$. This results in significant adverse cardiovascular changes (3). TTTS is associated with a high risk of perinatal mortality and morbidity if not treated, especially when the disease occurs in previable gestation and fetuses who survive can experience a wide range of cardiovascular, neurological and developmental disorders (4).

Timely diagnosis and treatment of TTTS are crucial in order to maximize perinatal outcome. TTTS is classically diagnosed in the second trimester with oligohydramnios/polyhydramnios sequence. Dekoninck et al. (5) have shown that the amniotic fluid volume varies according to gestational age, providing a rationale to lower cut-off values in order to diagnose polyhydramnios and consequently recognize TTTS at earlier gestational ages. The outcomes of MCDA twin pregnancies complicated by early TTTS are likely to be worse than those presenting at a later gestation. The evidence is controversial, with some researchers have reported similar mortality to TTTS presenting at a later stage (6). Moreover, the diagnostic criteria for polyhydramnios (deepest vertical pocket $\geq 8 \mathrm{~cm}$ ) currently used to diagnose TTTS are probably underestimating TTTS at earlier gestational age. These cases might also have worse outcomes due to the fact that they are not diagnosed as TTTS according to the current diagnostic criteria and, therefore, they are not offered prenatal intervention (7)..

The introduction of laser therapy of placental anastomoses in clinical practice has led to a significant reduction in perinatal mortality and neurological morbidity in twin pregnancies complicated by TTTS (8). Conversely, occlusion of the umbilical cord may represent an option in case of brain abnormalities or severe growth restriction of one twin, especially when far from viability, with the purpose of improving the outcome of the surviving twin (9). The current evidence does not support the practice of amnioreduction as a first line treatment in pregnancies complicated by TTTS (4). In general, an overall survival rate of $50-70 \%$ can be expected after laser therapy, while the risk of abnormal neurodevelopmental outcome ranges between 4 and 18\% (10). 
Several factors influence the outcome of twin pregnancies complicated by TTTS, including advanced Quintero stage, fetal growth restriction and early gestational age at treatment and preterm birth (PTB) $(11,12)$. Studies have reported conflicting results on the perinatal outcomes of twin pregnancies complicated by early TTTS. Baud et al. (13) have reported that double intrauterine demise occurs in $13 \%$, livebirth was achieved in $75 \%$ while the incidence of PPROM was 38\%. However, the corresponding figures in the study by Lecointre et al. (6) were 36\%, 55\% and $9 \%$, respectively

Despite its importance, there is no robust data yet on the actual risk of perinatal mortality and morbidity or on the optimal management of TTTS according to the gestational age at presentation. Therefore, the aim of this systematic review was to explore the outcome of twin pregnancies complicated by early TTTS.

\section{MATERIAL AND METHODS}

\section{Protocol, eligibility criteria, information sources and search}

This review was performed according to a priori designed protocol recommended for systematic reviews and meta-analysis. Medline, Embase, Clinicaltrials.gov and Cochrane Library databases were searched electronically in January 2019, utilizing combinations of the relevant medical subject heading (MeSH) terms, key words, and word variants for "twin pregnancies" and "transfusion" (Supporting Information Table S1). The search and selection criteria were restricted to English language. Reference lists of relevant articles and reviews were hand searched for additional reports. PRISMA (14) and MOOSE (15) guidelines were followed. The study was registered with the PROSPERO database (Registration number: CRD42019122948).

\section{Study selection, data collection and data items}

We considered for inclusion all studies (cohort studies, case series and randomized controlled trials if available) reporting data on outcomes of twin pregnancies affected by early (i.e. before 18 weeks) TTTS. Types of interventions evaluated were: expectant management, selective fetoscopic laser ablation of vascular anastomoses, amnioreduction (with or without septostomy) and selective fetal reduction (by intrafetal laser or radiofrequency ablation).

The primary outcome was mortality, including: 
1) Intra-uterine death (IUD) of either twin, defined as fetal loss after 20 weeks' gestation

2) Single IUD

3) Double IUD

4) Neonatal death, defined as the death of either twin up to 28 days of life

5) Perinatal death (PND), defined as IUD and neonatal death

The secondary outcomes were:

1) Overall neonatal morbidity, defined as the presence of at least one among: abnormal brain imaging, respiratory distress syndrome (RDS), admission to the neonatal intensive care unit or retinopathy of prematurity (ROP) in either twin

2) Neuromorbidity: defined as the presence of either intra-ventricular hemorrhage (IVH) or periventricular leukomalacia (PVL) of any type on post-natal imaging (ultrasound or magnetic resonance imaging)

3) Severe neuromorbidity, defined as the presence of either severe intraventricular leukomalacia (grade III and IV) or periventricular leukomalacia (grade II and III)

4) $\mathrm{RDS}$

5) Admission to neonatal intensive care unit

6) Intact survival, defined as survival free from neurological complications

7) $\mathrm{PTB}<32$ weeks of gestation

Two authors (CB, FGS) reviewed all abstracts independently. Agreement regarding potential relevance was reached by consensus; full text copies of those papers were obtained and the same two reviewers independently extracted relevant data regarding study characteristics and pregnancy outcomes. Inconsistencies were discussed by the reviewers and consensus reached or by discussion with a third author (FDA). If more than one study was published on the same cohort with identical endpoints, the report containing the most comprehensive information on the population was included to avoid overlapping populations. For those articles in which information was not reported but the methodology was such that this information would have been recorded initially, the authors were contacted.

\section{Difference between protocol and review}

Our review differed from our planned review because we could not assess some outcomes. In particular, recurrence of TTTS and twin anaemia polycythaemia sequence were not reported in the 
studies included in the meta-analysis. Similarly, data on gestational age at delivery (absolute value) and premature rupture of the membranes were not consistently reported in studies or not reported at all. We decided to report the outcome "preterm birth" as PTB $<32$ weeks because the data could be retrieved from a larger number of studies and is of clinical significance to distinguish between early PTB versus late preterm and term birth.

Moreover, we could not perform a subgroup analysis by disease stage because some studies were published before Quintero's staging system (11) was adopted or authors did not report the disease stage.

\section{Planned subgroup analysis}

All these outcomes were explored according to whether the management adopted (expectant, fetoscopic laser therapy, amnioreduction or selective reduction by intrafetal laser or radiofrequency ablation). Furthermore, we aimed to report all the outcomes in the donor and recipient twin separately. For the purpose of the analysis, studies on amnioreduction alone and those on amnioreduction associated with septostomy were considered in the same group. The reason for this choice was based upon the fact that perinatal survival has been reported to be similar in pregnancies treated with amnioreduction alone compared to septostomy in either twin.

\section{Quality assessment of the included studies}

Quality assessment of the included studies was performed using the Newcastle-Ottawa Scale (NOS) for case-control or cohort studies. According to NOS, each study is judged on three broad perspectives: the selection of the study groups; the comparability of the groups; and the ascertainment of outcome of interest. Assessment of the selection of a study includes the evaluation of the representativeness of the exposed cohort, selection of the non-exposed cohort, ascertainment of exposure and the demonstration that the outcome of interest was not present at the start of study. Assessment of the comparability of the study includes the evaluation of the comparability of cohorts based on the design or analysis. Finally, the ascertainment of the outcome of interest includes the evaluation of the type of the assessment of the outcome of interest, length and adequacy of follow-up. According to NOS a study can be awarded a maximum of one star for each numbered item within the Selection and Outcome categories. A maximum of two stars can be given for Comparability (16). Case series were evaluated with a modified version of NOS, which is based on 8 questions in the domains of selection, ascertainment, causality and reporting 
(Supporting Information Table S2). Although a formal score could be assigned giving a binary response to each question, the numeric representation of methodology quality was not considered appropriate and, as suggested by the authors, the overall final judgment was made based on questions 1, 2, 3, 7 and 8 as deemed most critical in this specific clinical scenario (17) .

\section{Statistical analyses}

We performed random-effect meta-analyses of proportions to estimate the pooled rates of each outcome in all the pregnancies and then according to the type of management reported (expectant, laser or selective reduction). Between study heterogeneity between study was explored using the I2 statistic, which represents the percentage of between-study variation that is due to heterogeneity rather than chance. A value of $0 \%$ indicates no heterogeneity is observed while values $>50 \%$ are associated with substantial heterogeneity. However, a random effects model was used for all metaanalyses because of the clinical heterogeneity identified between studies (18).. Potential publication bias was assessed using Egger's test and the creation of funnel plots for visual inspection (19). Tests for funnel plot asymmetry were not used when the total number of publications included for each outcome was less than ten, as the tests then lack power to detect real asymmetry (20). StatsDirect 3.0.171 (StatsDirect Ltd, Altrincham) and RevMan 5.3 (The Nordic Cochrane Centre, The Cochrane Collaboration, 2014) statistical software was used to analyse the data.

\section{RESULTS}

\section{General characteristics}

A total of 1649 articles were identified, 346 were assessed with respect to their eligibility for inclusion (Supporting Information Table S3) and 13 studies $(6,13,21-31)$ were included in the systematic review (Table 1, Figure 1). These 13 studies included 729 twin pregnancies affected by TTTS. TTTS occurred at $\leq 18$ weeks' gestation in $14.3 \%$, (95\% CI 11.9-17.0; 104/729), and for $3.0 \%(95 \%$ CI $2.0-4.5 ; 22 / 729)$ the onset was at $\leq 16$ weeks of gestation. Among the included studies, three reported the outcome of twin pregnancies affected by early TTTS in case of expectant management, 5 that of laser treatment of placental anastomoses, 8 that of amnioreduction and one that of cord occlusion. Four studies reported on more than one modality: three on amnioreduction and expectant management, one on amnioreduction and cord occlusion. 
The results of the quality assessment of the included studies using NOS or its modified version are presented in Table 2. Most of the included studies showed an overall good score regarding the selection and comparability of the study groups, and for ascertainment of the outcome of interest while case-series were scored low-quality. The main weaknesses of these studies were their retrospective design, small sample size and different gestational ages at intervention..

\section{Mortality}

The incidence of IUD was $19.0 \%(95 \%$ CI 2.6-45.5) in the MCDA twin pregnancies with TTTS which were managed expectantly, 32.4\% (95\% CI 16.5-50.7) in those who had laser treatment, and $12.5 \%$ (95\% CI 4.8-23.0) in those who had amnioreduction. Only one study reported the outcome of twins affected by early TTTS and treated with cord occlusion. This study included only one case and reported that cord occlusion was followed by the death of the co-twin (Table 3, Figure 2).

The incidence of neonatal death was $22.6 \%$ (95\% CI 4.2-49.8) in twins managed expectantly, $24.7 \%$ (95\% CI 0.5-80.3) in those who had laser and 20.2 (95\% CI 5.8-43.4) in those who had amnioreduction. No studies have reported outcomes in twin survivor who had cord occlusion of other co-twin (Table 3). Overall, the incidence of PND was 43.9\% (95\% CI 5.9-87.7) in twins managed expectantly, $47.3 \%$ (95\% CI 21.4-70.) in those treated with laser and $28.5 \%$ in those who had amnioreduction.

The incidence of single IUD was $0 \%$ (95\% CI 0-25.8) in twins managed expectantly, $14.8 \%$ (95\% CI 8.4-22.7) in those who had laser and 13.7\% (95\% CI 5.8-24.4) in those who had amnioreduction, while there was no information on the incidence of such outcomes in twins managed with cord occlusion. Conversely, double IUD occurred in 19.0\% (95\% CI 2.6-45.5) of twins managed expectantly, $15.8 \%$ (95\% CI 9.2-23.8) of those treated with laser and $7.3 \%$ (95\% CI 1.8-16.1) of those who had amnioreduction (Table 3).

When exploring the occurrence of IUD in the donor and recipient twin separately, IUD occurred in $28.0 \%$ (95\% CI 0.02-79.3) of cases both in the donor and recipient twin managed expectantly and in $24.1 \%$ (95\% CI 12.8-37.6) and 30.9\% (95\% CI 18.4-45.1) of those who had laser therapy, in $17.4 \%$ (95\% CI 5.2-34.8) and 10.4\% (95\% 1.6-25.4) of donor and recipient twin, respectively, in those having amnioreduction, while no data are available from studies on cord occlusion. 
Likewise, PND occurred in 54.0\% (95\% CI 11.4-93.2) of cases in the donor and recipient twin managed expectantly, in 37.7\% (95\% CI 11.2-68.9) of donors and 27.4\% (95\% CI 4.2-61.2) of recipients who had laser and in $30.5 \%$ of donors and $25.5 \%$ of the recipients who had amnioreduction.

\section{Preterm birth, morbidity and intact survival}

PTB occurred in 74.1\% (95\% CI 36.9-97.8) of pregnancies managed expectantly, 43.5\% (95\% CI 26.5-51.3) of those treated with laser and in $65.3 \%$ (95\% CI 45.8-80.7) of those who had amnioreduction, while the only case treated with cord occlusion gave birth before 32 weeks of gestation. Ascertainment of the risk of morbidity was affected by the very small number of included studies; only one study included 3 cases for which they reported information on morbidity in twins affected by early TTTS treated with laser. Likewise, the only study on cord occlusion did not report information of morbidity. Therefore, the figures for morbidity were reported only for twins managed expectantly or who had amnioreduction (Table 3).

Composite perinatal morbidity, defined as the diagnosis of any morbidity as listed before, occurred in $31.2 \%$ (95\% CI 17.8-75.4) of twins managed expectantly and 50.7\% (95\% CI 29.471..8) of those who had amnioreduction. The incidence of the different morbidities in twins affected by early TTTS according to the management option and disease status (donor vs recipient) are reported in Table 3.

Ascertainment of intact survival, defined as survival free from neurological complications, was also challenging. The analysis was limited by the very small number of included cases.

Furthermore, there was no study on twins affected by early TTTS managed expectantly and who had cord occlusion which explored such outcomes. In twins who had amnioreduction, 51.9\% (95\% CI 32.3-71.2) of cases did not have any neurological complication after birth, while all twins treated with laser had intact survival although only three cases were included for this outcome (Table 3).

\section{Sub-group analysis: TTTS $\leq 16$ weeks of gestation}

Sub-analysis including cases affected by TTTS $\leq 16$ weeks of gestation was limited by the small number of included cases and even smaller number of events which significantly affected the 
robustness of the results. The data on the different outcomes explored in MCDA twin pregnancies complicated by early TTTS $\leq 16$ weeks of gestation are reported in Table 4 .

\section{Sub-group analysis: TTTS $>18$ weeks of gestation}

In order to compare outcomes for early and late ( $>18$ weeks) TTTS that received a similar management, we performed a subgroup-analysis including cases affected by late TTTS (i.e. more than 18 weeks) from the included studies, as shown in Supporting Information Table S4. The incidence of IUD was $19.9 \%$ (95\% CI 7.8-35.7) after expectant management, $17 \%$ (95\% CI 2.3-41.3) and $12.5 \%$ (95\% CI 6.7-19.9) after laser and amnioreduction respectively. When exploring the occurrence of neonatal death, this was similar in expectancy and amnioreduction, i.e. $29.5 \%$ and $23.8 \%$ respectively and lower after laser therapy (7.6\%). Overall, the incidence of PND was 46.7\% (95\% CI 29.4-64.4) in twins managed expectantly, 34.2\% (95\% CI 25.3-61.5) in those treated with laser and $35.6 \%$ in those who had amnioreduction. The other outcomes are presented in Table S4.

\section{DISCUSSION}

The findings from this systematic review show that twin pregnancies complicated by early TTTS are at increased risk of perinatal mortality and morbidity. The incidence of PND was $43.9 \%$ in the twin pregnancies which were managed expectantly, $47.3 \%$ in those treated with laser and $28.5 \%$ in those who had amnioreduction, while no data could be extrapolated on cord occlusion. Composite perinatal morbidity, occurred in $31.2 \%$ of twins managed expectantly and $50.7 \%$ of those who had amnioreduction. PTB occurred in $74.1 \%$ of pregnancies managed expectantly, $43.5 \%$ of those treated with laser and in $65.3 \%$ of those who had amnioreduction.

Cases of TTTS after 18 weeks from the same studies were complicated by PND in $46.7 \%$ of cases after expectant management, $34.1 \%$ and $35.6 \%$ after laser and amioreduction respectively. PTB complicated $52.1 \%$ and $51.8 \%$ after expectancy and amnioreduction respectively and $34.2 \%$ after laser treatment.

This is, to our knowledge, the first systematic review exploring the outcome of pregnancies complicated by early TTTS. Thorough literature search aimed at identifying all the possible 
relevant studies, multitude of outcomes explored and stratification of the analysis according to the type of prenatal management adopted are the main strengths of this systematic review.

The small number of cases in some of the included studies, their retrospective non-randomized design, lack of standardized criteria for the antenatal surveillance and management of MCDA twin pregnancies complicated by early TTTS and therefore the overall low quality of many of them represent the major limitations of this systematic review. Assessment of the potential publication bias was also problematic because of the nature of the outcome evaluated (outcome rates, with the left-side limited to a value of zero), which limits the reliability of funnel plots, and the scarce number of individual studies, which strongly limits the reliability of formal tests.

Another major limitation of the present systematic review was the lack of stratification of the results according to the ultrasound staging of the disease. In MCDA pregnancies, TTTS can be classified in five stages based on findings from two-dimensional ultrasound and Doppler velocimetry in the umbilical artery, vein, and ductus venosus. Recent evidences suggest that the first stage of the disease in MCDA twins, characterized by the presence of oligohydramnios/polyhydramnios sequence on ultrasound, is associated with a better prognosis $(32,33)$. However, the small number of included studies did not allow performing this subgroup analysis. Sub-group analysis considering the type of prenatal management was also limited by the very small number of included cases and even smaller number of events, thus affecting the robustness of the results. Furthermore, the large majority of cases included in the expectant management studies came from old studies carried out before the Eurofetus trial was published, thus making it not feasible to perform a comprehensive comparison with the outcomes observed in more recent publications This is the reason why we did a sub-group analysis of late TTTS $(>18$ weeks) from the studies included in this meta-analysis and reported these data in Table S4.

Finally, subgroup analysis including only cases treated before 16 weeks of gestation was hindered by the even smaller number of included cases, and therefore, we could not stratify the analysis according to other pregnancy characteristics such as the disease stage or placental position. Despite these limitations, the present review represents the most comprehensive published estimate of the investigated outcomes in MCDA twin pregnancies complicated by early TTTS. 
TTTS is one of the major determinants of perinatal outcome in MCDA twin pregnancies (3). Introduction of laser therapy in clinical practice over the last two decades has significantly modified the natural history of this disease (34). Perinatal survival of fetuses with TTTS has been reported to be around $65 \%$ in recent non-randomized large series (8). In the present systematic review, PND complicated $47.3 \%$ of fetuses affected by early TTTS. These figures suggest a relatively higher risk of death in twin pregnancies affected by early TTTS. A likely explanation for such phenomenon might be that early TTTS represents a more severe spectrum of the disease. Another explanation could be the prolonged exposure to the fetuses to the massive hemodynamic changes, which occur in TTTS in case of early disease. In this scenario, early TTTS may represent a peculiar clinical phenotype of the disease characterized by a more pronounced cardiovascular derangements leading to a higher risk of adverse perinatal outcome. Likewise, the high rate of PTB observed in these pregnancies could account for the increased risk of PND reported in the present review.

Amnioreduction does not represent the first line therapy for TTTS as laser treatment has been shown to be associated with a higher perinatal survival in the Eurofetus trial (35), although it may represent an option in case of TTTS stage 2 or higher in conditions where transfer to a centre that performs laser therapy is not possible (36). Survival rates of about $50 \%$ have been reported following amnioreduction (37). However, such practice, especially when repeated, is associated with a high risk of PTB and does not alter the natural history of the disease. Overall, the survival rates after amnioreduction have been reported to be around 50\% in the published literature, irrespective of the stage and gestational age at onset of the disease. In the present systematic review, PND occurred in 34\% of pregnancies affected by early TTTS while PTB complicated 66\% of cases. The high incidence of PTB observed in the present review is likely to be the consequence of the need for repeated procedures and does not support a policy of amnioreduction in pregnancies affected by early TTTS. In fact, although the results suggest a relatively lower PND rate compared to the group managed with laser therapy, these groups are not comparable, since expectant management and/or amnioreduction may be chosen for milder forms of the disease but also when laser was not available, in order to alleviate maternal symptoms due to polyhydramnios, or to reduce the risk of PTB or a mix of these reasons, introducing a selection bias. This is an inherent bias associated with most of the observational studies. Moreover, data on amnioreduction derived from old studies that were conducted before the Eurofetus trial which showed that laser 
treatment is associated with higher survival rates (38) and a reduction in the risk of long-term major neurological impairment at the age of 5 years (39).

The most interesting and challenging group is represented by very early cases, when TTTS occurs before 16 weeks. In this group the diagnosis is still a challenge and the Quintero staging system is not applicable. In fact, clinicians often diagnose TTTS at this early gestation based on other features such as oligohydramnios (stuck twin) with amniotic fluid discordance, distended bladder with/without abnormal fetal Dopplers with/without tricuspid regurgitation or cardiomegaly and with a deep vertical pocket (DVP of $\geq 6 \mathrm{~cm}$ ) in the larger twin. This is why new cut-off values for DVP are proposed before 18 weeks, lowering the DVP cut-off of diagnosing polyhydramnios to 6 $\mathrm{cm}(7,11)$

Another challenging query is whether laser treatment before 16 weeks increases the chances of preterm prelabour rupture of membranes (PPROM) and therefore it might be better to postpone laser therapy after 16 weeks' gestation, or whether using equipment, such as embryoscope or smaller fetoscope, it is as safe as performed after 16 weeks. We tried to answer this question but data on these pregnancies are very limited (only 14 pregnancies treated with laser and 7 treated with amnioreduction). Data regarding the PPROM rates $<7$ days after laser were reported in 13/14 pregnancies with an incidence of $23.1 \%$ (3/13). Furthermore, only two studies (3 pregnancies) reported this data after amnioreduction precluding any conclusion. The question regarding the higher chance of PPROM cannot be truly answered, however the high rates of PTB $(69 \%)$ seem to indicate that postponing laser therapy after 16 weeks might be a reasonable option.

Interruption of the blood flow in the umbilical cord through radiofrequency ablation or bipolar umbilical cord coagulation represents an effective procedure when one fetus is severely jeopardized and delivery is not yet an option, in order to maximize the outcome of the surviving twin (40). In the present review, we could not consistently report the incidence of perinatal mortality in twin pregnancies complicated by TTTS undergoing cord occlusion in view of the very small number of included cases and lack of ascertainment of most of the observed outcomes. The current practice includes that cord occlusion should not be offered as the first line treatment in case of early TTTS unless there is imaging evidence of major fetal compromise such as severe ventriculomegaly, growth restriction or impending fetal death. 
In the present systematic review, we could not systematically report objective data on morbidity in twin pregnancies affected by early TTTS. One of the major challenges in ascertaining the outcome of MCDA twin pregnancies complicated by TTTS is the wide heterogeneity in outcomes definition, post-natal assessment and time at follow up. Furthermore, the large majority of previously published studies focused on mortality while there is a generically lack of data on morbidity. This may be partially explained by the fact that TTTS is a condition associated with a very high risk of mortality if untreated. Therefore, the majority of published studies focused on mortality. However, with an improving rate of survival, there is now need for objective data on short- and long-term morbidities in order to be able to provide the relevant outcomes data which the parents need before making an informed decision. We have recently published the core outcome set in TTTS (41), aiming to improve the quality of reporting future studies.

\section{CONCLUSION}

Twin pregnancies complicated by early TTTS are at substantial risk of perinatal mortality and morbidity. However, in view of the small number of included cases, heterogeneity in outcome definition, reporting and time at follow-up, the present review does not allow us to extrapolate an objective evidence on the optimal prenatal management in these pregnancies. Future studies using standardized definitions and objective protocols of prenatal diagnosis and management, including post-natal follow-up, are needed in order to provide more accurate estimates of the clinically relevant perinatal outcomes. This should enable us to provide better individualized counselling and optimal management of twin pregnancies complicated by early TTTS.

\section{REFERENCES}

1. Mosquera C, Miller RS, Simpson LL. Twin-twin transfusion syndrome. Semin Perinatol. 2012;36:1829.

2. Lewi L, Deprest J, Hecher K. The vascular anastomoses in monochorionic twin pregnancies and their clinical consequences. Am J Obstet Gynecol. 2013; 208: 19-30

3. Society for Maternal-Fetal Medicine, Simpson LL. Twin-twin transfusion syndrome. Am J Obstet Gynecol. 2013;208:3-18. 
4. Roberts D, Gates S, Kilby M, Neilson JP. Interventions for twin-twin transfusion syndrome: a Cochrane review. Ultrasound Obstet Gynecol. 2008;31:701-11.

5. Dekoninck P, Deprest J, Lewi P, et al. Gestational age-specific reference ranges for amniotic fluid assessment in monochorionic diamniotic twin pregnancies. Ultrasound Obstet Gynecol. 2013;41:64952.

6. Lecointre L, Sananes N, Weingertner AS, et al. Fetoscopic laser coagulation for twin-twin transfusion syndrome before 17 weeks' gestation: laser data, complications and neonatal outcome. Ultrasound Obstet Gynecol. 2014;44:299-303.

7. Khalil A. Modified diagnostic criteria for twin-to-twin transfusion syndrome prior to 18 weeks' gestation: time to change? Ultrasound Obstet Gynecol. 2017;49:804-805.

8. Diehl W, Diemert A, Grasso D, Sehner S, Wegscheider K, Hecher K. Fetoscopic laser coagulation in 1020 pregnancies with twin-twin transfusion syndrome demonstrates improvement in double-twin survival rate. Ultrasound Obstet Gynecol. 2017;50:728-735.

9. Rossi AC, D'Addario V. Umbilical cord occlusion for selective feticide in complicated monochorionic twins: a systematic review of literature. Am J Obstet Gynecol. 2009;200:123-9.

10. Van Klink J, Koopman H, Rijken M, Middeldorp J, Oepkes D, Lopriore E. Long-term neurodevelopmental outcome in survivors of twin-to-twin transfusion syndrome. Twin Research and Human Genetics. 2016;19:255-261.

11. Quintero RA, Dickinson JE, Morales WJ, et al. Stage-based treatment of twin-twin transfusion syndrome. Am J Obstet Gynecol. 2003;188:1333-40.

12. Lopriore E, Ortibus E, Acosta-Rojas R, et al. Risk factors for neurodevelopment impairment in twintwin transfusion syndrome treated with fetoscopic laser surgery. Obstet Gynecol. 2009;113:361-6.

13. Baud D, Windrim R, Keunen J, et al. Fetoscopic laser therapy for twin-twin transfusion syndrome before 17 and after 26 weeks' gestation. Am J Obstet Gynecol. 2013;208:197.e1-7.

14. Prisma statement. http://www.prisma-statement.org/ [accessed 10 July 2016].

15. Stroup DF, Berlin JA, Morton SC, et al. Meta-analysis of observational studies in epidemiology: a proposal for reporting. Meta-analysis Of Observational Studies in Epidemiology (MOOSE) group. JAMA. 2000;283:2008-12.

16. Wells GA, Shea B, O'Connell D, et al. The Newcastle-Ottawa Scale (NOS) for Assessing the Quality of Nonrandomised Studies in Meta-analyses.

http://www.ohri.ca/programs/clinical_epidemiology/oxford.asp [accessed 17 feb 2014].

17. Murad MH, Sultan S, Haffar S, Bazerbachi F. Methodological quality and synthesis of case series and case reports. BMJ Evid Based Med. 2018;23:60-63.

18. Higgins J, Thompson S, Deeks J, Altman D. Statistical heterogeneity in systematic reviews of clinical trials: a critical appraisal of guidelines and practice. J Health Serv Res Policy. 2002;7:51-61. 
19. Egger M, Davey Smith G, Schneider M, Minder C. Bias in meta-analysis detected by a simple, graphical test. BMJ. 1997; 315: 629-634.

20. Hunter JP, Saratzis A, Sutton AJ, Boucher RH, Sayers RD, Bown MJ. In meta-analyses of proportion studies, funnel plots were found to be an inaccurate method of assessing publication bias. $J$ ClinEpidemiol. 2014; 67: 897-903.

21. Blaicher W, Ulm B, Ulm M, Kuhle S, Deutinger J, Bernaschek G. The twin-twin transfusion syndrome - an unsolved problem. Ultraschall Med. 2002;23:108-12.

22. Dennis LG, Winkler CL. Twin-to-twin transfusion syndrome: aggressive therapeutic amniocentesis. Am J Obstet Gynecol. 1997;177:342-7; discussion 347-9.

23. Elliott JP, Urig MA, Clewell WH. Aggressive therapeutic amniocentesis for treatment of twin-twin transfusion syndrome. Obstet Gynecol. 1991;77:537-40.

24. Has R, Akhan S, Topuz S, Ermiş H, Iyibozkurt C, Ibrahimoğlu L. Therapeutic amniocentesis for treatment of twin-twin transfusion syndrome. Arch Gynecol Obstet. 2005;271:22-5.

25. Johnson JR, Rossi KQ, O'Shaughnessy RW. Amnioreduction versus septostomy in twin-twin transfusion syndrome. Am J Obstet Gynecol. 2001;185:1044-7.

26. Lim YK, Tan TY, Zuzarte R, Daniel ML, Yeo GS. Outcomes of twin-twin transfusion syndrome managed by a specialised twin clinic. Singapore Med J. 2005;46:401-6.

27. Mahieu-Caputo D, Salomon LJ, Le Bidois J, et al. Fetal hypertension: an insight into the pathogenesis of the twin-twin transfusion syndrome. Prenat Diagn. 2003;23:640-5.

28. Mari G, Detti L, Oz U, Abuhamad AZ. Long-term outcome in twin-twin transfusion syndrome treated with serial aggressive amnioreduction. Am J Obstet Gynecol. 2000;183:211-7.

29. Sebire NJ, D'Ercole C, Carvelho M, Sepulveda W, Nicolaides KH. Inter-twin membrane folding in monochorionic pregnancies. Ultrasound Obstet Gynecol. 1998;11:324-7.

30. Sepulveda W, Wong AE, Dezerega V, Devoto JC, Alcalde JL. Endoscopic laser surgery in severe second-trimester twin-twin transfusion syndrome: a three-year experience from a Latin American center. Prenat Diagn. 2007;27:1033-8.

31. Willruth A, Geipel A, Berg C, Fimmers R, Gembruch U. Assessment of cardiac function in monochorionic diamniotic twin pregnancies with twin-to-twin transfusion syndrome before and after fetoscopic laser photocoagulation using Speckle tracking. Ultraschall Med. 2013;34:162-8.

32. Khalil A, Cooper E, Townsend R, Thilaganathan B. Evolution of Stage 1 Twin-to-Twin Transfusion Syndrome (TTTS): Systematic Review and Meta-Analysis. Twin Res Hum Genet. 2016;19:207-16.

33. Washburn EE, Sparks TN, Gosnell KA, Rand L, Gonzalez JM, Feldstein VA. Stage I Twin-Twin Transfusion Syndrome: Outcomes of Expectant Management and Prognostic Features. Am J Perinatol. 2018;35:1352-1357.

This article is protected by copyright. All rights reserved 
34. Ville Y, Hecher K, Gagnon A, SebireN, Hyett J, Nicolaides K. Endoscopic laser coagulation in the management of severe twin-to-twin transfusion syndrome. Br J Obstet Gynaecol. 1998;105:446-53.

35. Senat MV, Deprest J, Boulvain M, Paupe A, Winer N, Ville Y. Endoscopic laser surgery versus serial amnioreduction for severe twin-to-twin transfusion syndrome. N Engl J Med. 2004;351:136-44.

36. Khalil A, Rodgers M, Baschat A, et al. ISUOG Practice Guidelines: role of ultrasound in twin pregnancy. Ultrasound Obstet Gynecol 2016;47:247-263

37. Mari G, Roberts A, Detti L, et al. Perinatal morbidity and mortality rates in severe twin-twin transfusion syndrome: results of the International Amnioreduction Registry. Am J Obstet Gynecol. 2001;185:708-15.

38. Senat MV, Deprest J, Boulvain M, Paupe A, Winer N, Ville Y. Endoscopic laser surgery versus serial amnioreduction for severe twin-to-twin transfusion syndrome. N Engl J Med. 2004;351:136-44

39. Salomon LJ, Ortqvist L, Aegerter P, et al. Long-term developmental follow-up of infants who participated in a randomized clinical trial of amniocentesis vs laser photocoagulation for the treatment of twin-to-twin transfusion syndrome. Am J Obstet Gynecol. 2010;203:444.e1-7

40. Bebbington MW, Danzer E, Moldenhauer J, Khalek N, Johnson MP. Radiofrequency ablation vs bipolar umbilical cord coagulation in the management of complicated monochorionic pregnancies. Ultrasound Obstet Gynecol. 2012;40:319-24.

41. Perry H, Duffy JMN, Umadia O, Khalil A; International Collaboration to Harmonise Outcomes for Twin-Twin Transfusion Syndrome (CHOOSE). Outcome reporting across randomized trials and observational studies evaluating treatments fortwin-twin transfusion syndrome: systematic review. Ultrasound Obstet Gynecol.2018;52:577-585.

\section{Supporting Information legends}

Table S1. Search strategy.

Table S2: Tool for evaluating the methodological quality of case reports and case series** (15).

Table S3. Studies assessed with respect to their eligibility for inclusion.

Table S4: Pooled proportions for the incidence of the different adverse outcomes explored in the present review in monochorionic diamniotic (MCDA) twin pregnancies complicated by TTTS diagnosed at or beyond 18 weeks of gestation.

This article is protected by copyright. All rights reserved 


\section{Table and figure legends}

Table 1. General characteristics of the included studies.

Table 2 - Quality assessment of the included studies according to Newcastle-Ottawa Scale (NOS)*or to modified Newcastle-Ottawa, Pierson and Bradford Hill scales for case series**.

Table 3: Pooled proportions (PP) for the incidence of the different adverse outcomes explored in the present review in monochorionic diamniotic (MCDA) twin pregnancies complicated by early TTTS.

Table 4: Pooled proportions for the incidence of the different adverse outcomes explored in the present review in monochorionic diamniotic (MCDA) twin pregnancies complicated by early TTTS occurring before 16 weeks of gestation.

Figure 1 - Flow chart illustrating identification of studies included in this systematic review.

*some studies reported on more than one management.

Figure 2 - Graphical representation of the Pooled proportions for the incidence of perinatal death (PND) according to management in pregnancies complicated by early TTTS. 
Table 1. General characteristics of the included studies

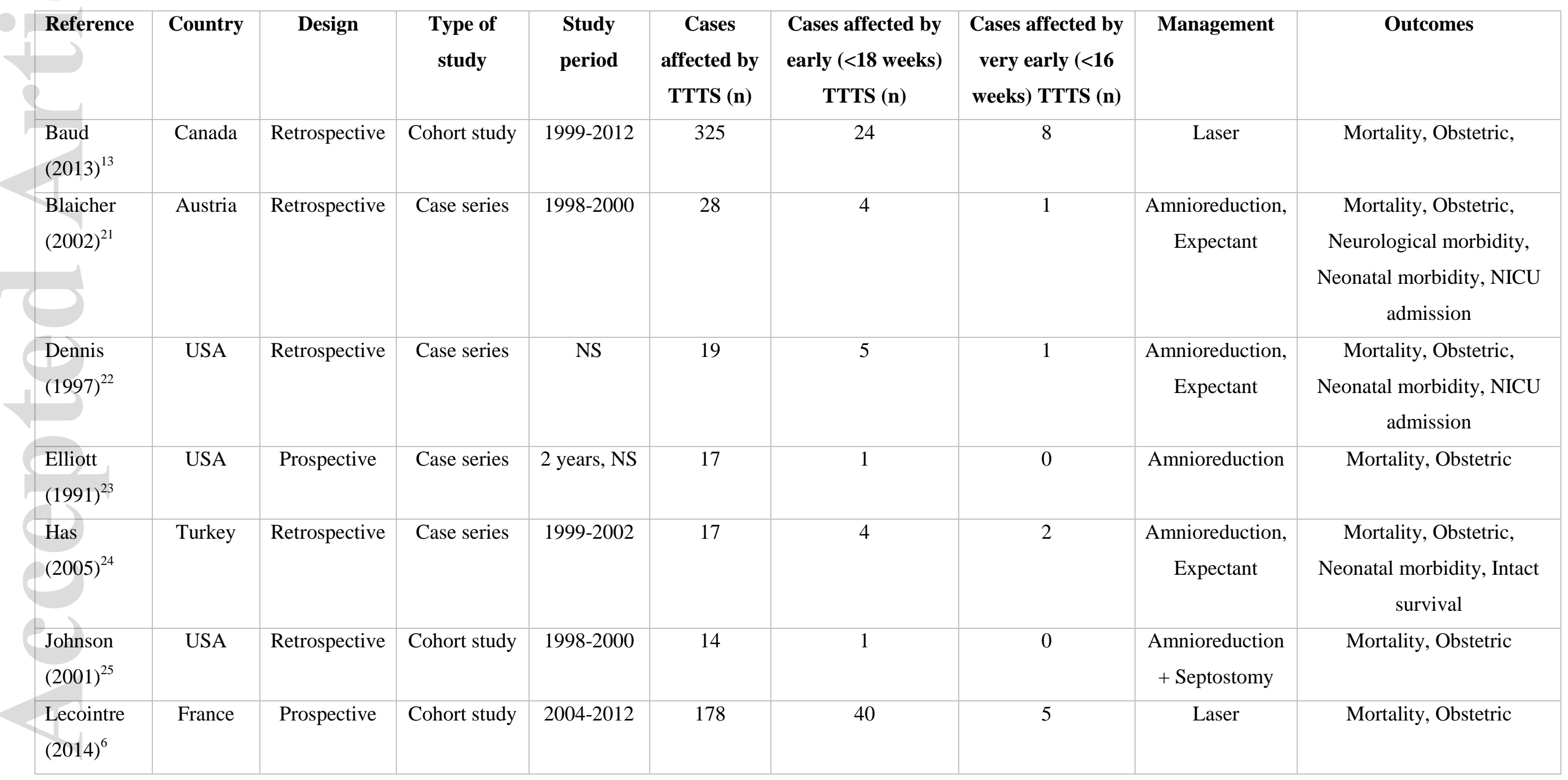

This article is protected by copyright. All rights reserved 


\begin{tabular}{|c|c|c|c|c|c|c|c|c|c|}
\hline${ }_{(2005)^{26}}^{\operatorname{Lim}}$ & Singapore & Retrospective & Case series & $2002-2003$ & 11 & 6 & 0 & $\begin{array}{l}\text { Amnioreduction } \\
+ \text { Septostomy, } \\
\text { Cord Occlusion }\end{array}$ & $\begin{array}{l}\text { Mortality, Obstetric, } \\
\text { Neurological morbidity, } \\
\text { Neonatal morbidity, } \\
\text { Respiratory morbidity, } \\
\text { NICU admission }\end{array}$ \\
\hline $\begin{array}{l}\text { Mahieu-Capı } \\
(2003)^{27}\end{array}$ & France & Prospective & Cohort study & $1993-2000$ & 23 & 2 & 1 & $\begin{array}{l}\text { Amnioreduction } \\
+ \text { Septostomy }\end{array}$ & Mortality, Obstetric \\
\hline $\begin{array}{l}\text { Mari } \\
(2000)^{28}\end{array}$ & USA & Prospective & Case series & 1990-1997 & 30 & 11 & 3 & Amnioreduction & $\begin{array}{c}\text { Mortality, Obstetric, Intact } \\
\text { survival }\end{array}$ \\
\hline $\begin{array}{l}\text { Sebire } \\
(1998)^{29}\end{array}$ & UK & Prospective & $\begin{array}{l}\text { Case-control } \\
\text { study }\end{array}$ & NS & 23 & 3 & 1 & Laser & Mortality, Obstetric \\
\hline $\begin{array}{l}\text { Sepulveda } \\
(2007)^{30}\end{array}$ & Chile & Prospective & Case series & $2003-2006$ & 33 & 1 & 0 & Laser & Mortality, Obstetric \\
\hline
\end{tabular}

This article is protected by copyright. All rights reserved 
Table 2 - Quality assessment of the included studies according to Newcastle-Ottawa Scale (NOS)*or to modified Newcastle-Ottawa, Pierson and Bradford Hill scales for case series**.

\begin{tabular}{|c|c|c|c|c|}
\hline Author & Year & Selection & Comparability & Outcome \\
\hline $\operatorname{Baud}^{18 *}$ & 2013 & 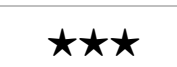 & $\star \star$ & $\star \star \star \star$ \\
\hline Blaicher ${ }^{19} * *$ & 2002 & \multicolumn{3}{|c|}{ Low quality } \\
\hline Dennis $^{20} * *$ & 1997 & \multicolumn{3}{|c|}{ Low quality } \\
\hline Elliott $^{21} * *$ & 1991 & \multicolumn{3}{|c|}{ Low quality } \\
\hline $\operatorname{Has}^{22} * *$ & 2005 & \multicolumn{3}{|c|}{ Low quality } \\
\hline Johnson $^{23} *$ & 2001 & $\star \star$ & $\star$ & $\star \star$ \\
\hline Lecointre $^{5 *}$ & 2014 & $\star \star \star \star$ & $\star \star$ & $\star \star \star$ \\
\hline $\operatorname{Lim}^{24} * *$ & 2005 & \multicolumn{3}{|c|}{ Low quality } \\
\hline Mahieu-Caputo $^{25} *$ & 2003 & $\star \star$ & $\star$ & $\star \star$ \\
\hline $\operatorname{Mari}^{26} * *$ & 2000 & \multicolumn{3}{|c|}{ Low quality } \\
\hline Sebire $^{27} *$ & 1998 & $\star$ & $\star$ & $\star \star \star$ \\
\hline Sepulveda ${ }^{28 * *}$ & 2007 & \multicolumn{3}{|c|}{ Low quality } \\
\hline Willruth $^{29} *$ & 2013 & $\star \star$ & $\star$ & $\star \star$ \\
\hline
\end{tabular}

* Cohort/Case-control studies assessed according to Newcastle-Ottawa Scale (NOS) (assessment based on selection/comparability/exposure-outcome. Highest scores are 4 for selection, 2 for comparability and 3 for exposure-outcome) (14).

**Case series/reports assessed with a tool that published at BMJ Evidence-Based-Medicine Journal on April 2018 (Supplementary Table 2). Authors specifically mention about not to use an aggregate score for this tool on the other hand making overall judgment like we do (low or high quality) is much more appropriate (15)

This article is protected by copyright. All rights reserved 
Table 3: Pooled proportions (PP) for the incidence of the different adverse outcomes explored in the present review in monochorionic diamniotic (MCDA) twin pregnancies complicated by early twin to twin transfusion syndrome.

\begin{tabular}{|c|c|c|c|c|c|c|c|c|c|c|c|c|c|}
\hline \multirow[b]{2}{*}{ Outcome } & \multirow[b]{2}{*}{ Studies (n) } & \multicolumn{3}{|c|}{ Expectant management } & \multicolumn{3}{|c|}{ Laser therapy } & \multicolumn{3}{|c|}{ Amnioreduction } & \multicolumn{3}{|c|}{ Cord occlusion } \\
\hline & & Fetuses (n) & $\begin{array}{c}\text { PP (95\% } \\
\text { CI) }\end{array}$ & $\mathrm{I}^{2}(\%)$ & Fetuses (n) & $\begin{array}{c}\text { PP }(95 \% \\
\text { CI })\end{array}$ & $I^{2}(\%)$ & Fetuses (n) & $\begin{array}{c}\text { PP }(95 \% \\
\text { CI })\end{array}$ & $\begin{array}{c}\mathbf{I}^{2}(\% \\
)\end{array}$ & Fetuses (n) & PP (95\% CI) & $I^{2}(\%)$ \\
\hline \multicolumn{14}{|c|}{ Mortality } \\
\hline IUD (overall) & $3,4,7,1$ & $2 / 10$ & $\begin{array}{c}19.00 \\
(2.6-45.5)\end{array}$ & 76.5 & $27 / 92$ & $\begin{array}{c}32.39 \\
(16.5-50.7)\end{array}$ & 27.8 & $6 / 48$ & $\begin{array}{c}12.46 \\
(4.8-23.0)\end{array}$ & 0 & $1 / 1$ & $\begin{array}{c}100 \\
(2.5-100)\end{array}$ & - \\
\hline Single IUD & $3,4,7,1$ & $0 / 10$ & $0(0-25.8)$ & 0 & $13 / 92$ & $\begin{array}{c}14.82 \\
(8.4-22.7)\end{array}$ & 0 & $4 / 48$ & $\begin{array}{c}13.73 \\
(5.8-24.4)\end{array}$ & 0 & - & - & - \\
\hline Double IUD & $3,4,7,1$ & $2 / 10$ & $\begin{array}{c}19.00 \\
(2.6-45.5)\end{array}$ & 76.5 & $14 / 92$ & $\begin{array}{c}15.83 \\
(9.2-23.8)\end{array}$ & 0 & $2 / 48$ & $\begin{array}{c}7.31 \\
(1.8-16.1)\end{array}$ & 0 & - & - & - \\
\hline IUD donor & $3,3,6,0$ & $1 / 5$ & $\begin{array}{c}27.97 \\
(0.02-79.3)\end{array}$ & 44.8 & $10 / 43$ & $\begin{array}{c}24.12 \\
(12.8-37.6)\end{array}$ & 0 & $3 / 23$ & $\begin{array}{c}17.41 \\
(5.2-34.8)\end{array}$ & 0 & - & - & - \\
\hline IUD recipient & $3,3,6,0$ & $1 / 5$ & $\begin{array}{c}27.97 \\
(0.02-79.3)\end{array}$ & 44.8 & $13 / 43$ & $\begin{array}{c}30.92 \\
(18.4-45.1)\end{array}$ & 0 & $1 / 23$ & $\begin{array}{c}10.40 \\
(1.6-25.4)\end{array}$ & 0 & - & - & - \\
\hline (2) & & & & & & & & & & & & & \\
\hline NND (overall) & $3,3,7,0$ & $2 / 10$ & $\begin{array}{c}22.56 \\
(4.2-49.8)\end{array}$ & 0 & $2 / 12$ & $\begin{array}{c}24.68 \\
(0.5-80.3)\end{array}$ & 77.9 & $8 / 48$ & $\begin{array}{c}20.14 \\
(5.8-43.4)\end{array}$ & 53.1 & - & - & - \\
\hline Single NND & $3,3,7,0$ & $0 / 10$ & $0(0-25.8)$ & 0 & $0 / 12$ & $0(0-22.5)$ & 0 & $2 / 48$ & $\begin{array}{c}7.43 \\
(1.9-16.3)\end{array}$ & 0 & - & - & - \\
\hline Double NND & $3,3,7,0$ & $2 / 10$ & $\begin{array}{c}15.36 \\
(12.9-40.7)\end{array}$ & 0 & $2 / 12$ & $\begin{array}{c}24.68 \\
(0.5-80.3)\end{array}$ & 77.9 & $6 / 48$ & $\begin{array}{c}14.75 \\
(1.7-37.5)\end{array}$ & 66.8 & - & - & - \\
\hline NND donor & $3,3,6,0$ & $1 / 5$ & 25.88 & 0 & $1 / 6$ & 24.08 & 48.4 & $3 / 24$ & 13.27 & 40.3 & - & - & - \\
\hline
\end{tabular}

This article is protected by copyright. All rights reserved 


\begin{tabular}{|c|c|c|c|c|c|c|c|c|c|c|c|c|c|}
\hline 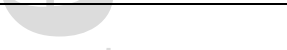 & & & $(2.2-63.1)$ & & & $(7.2-73.0)$ & & & $(3.0-29.4)$ & & & & \\
\hline NND (recipient) & $3,3,6,0$ & $1 / 5$ & $\begin{array}{c}25.88 \\
(2.2-63.1)\end{array}$ & 0 & $1 / 6$ & $\begin{array}{c}24.08 \\
(7.2-73.0)\end{array}$ & 48.4 & $4 / 24$ & $\begin{array}{c}20.80 \\
(7.3-38.9)\end{array}$ & 1 & - & - & - \\
\hline PND (overall) & $3,4,7$ & $4 / 10$ & $\begin{array}{c}43.90 \\
(5.9-87.0)\end{array}$ & 58.4 & $21 / 60$ & $\begin{array}{c}47.32 \\
(21.4-70.0)\end{array}$ & 57.1 & $14 / 48$ & $\begin{array}{c}28.47 \\
(17.1-41.4)\end{array}$ & 44.5 & $1 / 1$ & $\begin{array}{c}100 \\
(2.5-100)\end{array}$ & - \\
\hline Single PND & $3,4,7$ & $0 / 10$ & $0(0-25.8)$ & 0 & $9 / 60$ & $\begin{array}{c}16.07 \\
(8.1-26.2)\end{array}$ & 0 & $2 / 48$ & $\begin{array}{c}7.13 \\
(1.8-15.7)\end{array}$ & 0 & - & - & - \\
\hline Double PND & $3,4,7$ & $4 / 10$ & $\begin{array}{c}43.90 \\
(5.9-87.0)\end{array}$ & & $12 / 60$ & $\begin{array}{c}28.92 \\
(6.7-58.8)\end{array}$ & 64.2 & $12 / 48$ & $\begin{array}{c}24.79 \\
(14.1-37.4)\end{array}$ & 40.4 & - & - & - \\
\hline PND donor & $2,3,7$ & $2 / 4$ & $\begin{array}{c}53.99 \\
(11.4-93.2)\end{array}$ & 13.2 & $10 / 27$ & $\begin{array}{c}37.66 \\
(11.2-68.9)\end{array}$ & 29.9 & $6 / 21$ & $\begin{array}{c}30.51 \\
(13.6-50.7)\end{array}$ & 4.7 & - & - & - \\
\hline PND recipient & $2,3,7$ & $2 / 4$ & $\begin{array}{c}53.99 \\
(11.4-93.2)\end{array}$ & 13.2 & $7 / 27$ & $\begin{array}{c}27.34 \\
(12.9-44.9)\end{array}$ & 39.4 & $5 / 21$ & $\begin{array}{c}25.46 \\
(10.4-44.4)\end{array}$ & 0 & - & - & - \\
\hline 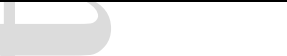 & & & & & & Preterm birth & & & & & & & \\
\hline PTB <32 weeks & $3,5,8,1$ & $4 / 5$ & $\begin{array}{c}74.12 \\
(36.9-97.8)\end{array}$ & 0 & $30 / 70$ & $\begin{array}{c}43.53 \\
(26.5-61.3)\end{array}$ & 35.6 & $16 / 25$ & $\begin{array}{c}65.25 \\
(45.8-80.7)\end{array}$ & 2.7 & $1 / 1$ & $\begin{array}{c}100 \\
(2.5-100)\end{array}$ & - \\
\hline & & & & & & Morbidity & & & & & & & \\
\hline $\begin{array}{l}\text { Composite } \\
\text { morbidity } \\
\text { (overall) }\end{array}$ & $2,1,4,0$ & $2 / 6$ & $\begin{array}{c}31.24 \\
(17.8-75.4)\end{array}$ & 31.8 & $0 / 3$ & $\begin{array}{c}0 \\
(0-70.8)\end{array}$ & - & $9 / 18$ & $\begin{array}{c}50.67 \\
(29.4-71.8)\end{array}$ & 0 & - & - & - \\
\hline $\begin{array}{l}\text { Composite } \\
\text { morbidity }\end{array}$ & $2,1,3,0$ & $1 / 3$ & $\begin{array}{c}35.49 \\
(2.2-81.7)\end{array}$ & 0 & $0 / 1$ & $\begin{array}{c}0 \\
(0-97.5)\end{array}$ & - & $4 / 7$ & $\begin{array}{c}56.91 \\
(24.6-86.2)\end{array}$ & 0 & - & - & - \\
\hline
\end{tabular}

This article is protected by copyright. All rights reserved 


\begin{tabular}{|c|c|c|c|c|c|c|c|c|c|c|c|c|c|}
\hline (donor) & & & & & & & & & & & & & \\
\hline $\begin{array}{l}\text { Composite } \\
\text { morbidity } \\
\text { (recipient) }\end{array}$ & $2,1,3,0$ & $1 / 3$ & $\begin{array}{c}35.49 \\
(2.2-81.7)\end{array}$ & 0 & $0 / 1$ & $\begin{array}{c}0 \\
(0-97.5)\end{array}$ & - & $3 / 7$ & $\begin{array}{c}40.81 \\
(12.2-73.4)\end{array}$ & 57.6 & - & - & - \\
\hline 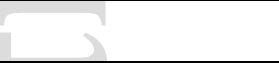 & & & & & & & & & & & & & \\
\hline $\begin{array}{c}\text { Neuromorbidity } \\
\text { (overall) }\end{array}$ & $1,1,20$ & $0 / 2$ & $\begin{array}{c}0 \\
(0-84.2)\end{array}$ & - & $0 / 3$ & $\begin{array}{c}0 \\
(0-70.8)\end{array}$ & - & $3 / 10$ & $\begin{array}{c}32.40 \\
(14.8-53.1)\end{array}$ & 0 & - & - & - \\
\hline $\begin{array}{l}\text { Neuromorbidity } \\
\text { (donor) }\end{array}$ & $1,1,0,0$ & $0 / 1$ & $\begin{array}{c}0 \\
(0-97.5)\end{array}$ & $0 / 1$ & $0 / 1$ & $\begin{array}{c}0 \\
(0-97.5)\end{array}$ & - & - & - & - & - & - & - \\
\hline $\begin{array}{l}\text { Neuromorbidity } \\
\text { (recipient) }\end{array}$ & $1,1,0,0$ & $0 / 1$ & $\begin{array}{c}0 \\
(0-97.5)\end{array}$ & $0 / 1$ & $0 / 1$ & $\begin{array}{c}0 \\
(0-97.5)\end{array}$ & - & - & - & - & - & - & - \\
\hline 1 & & & & & & & & & & & & & \\
\hline $\begin{array}{c}\text { Severe } \\
\text { neuromorbidity } \\
\text { (overall) }\end{array}$ & $1,1,1,0$ & $0 / 2$ & $\begin{array}{c}0 \\
(0-84.2)\end{array}$ & - & $0 / 3$ & $\begin{array}{c}0 \\
(0-70.8)\end{array}$ & - & $1 / 4$ & $\begin{array}{c}25.00 \\
(0.6-80.6)\end{array}$ & & - & - & - \\
\hline $\begin{array}{c}\text { Severe } \\
\text { neuromorbidity } \\
\text { (donor) }\end{array}$ & $1,1,0,0$ & $0 / 1$ & $\begin{array}{c}0 \\
(0-97.5)\end{array}$ & $0 / 1$ & $0 / 1$ & $\begin{array}{c}0 \\
(0-97.5)\end{array}$ & - & - & & - & - & - & - \\
\hline $\begin{array}{c}\text { Severe } \\
\text { neuromorbidity } \\
\text { (recipient) }\end{array}$ & $1,1,0,0$ & $0 / 1$ & $\begin{array}{c}0 \\
(0-97.5)\end{array}$ & $0 / 1$ & $0 / 1$ & $\begin{array}{c}0 \\
(0-97.5)\end{array}$ & - & - & - & - & - & - & - \\
\hline$y$ & & & & & & & & & & & & & \\
\hline RDS (overall) & $0,1,1,0$ & - & - & - & $0 / 3$ & $\begin{array}{c}0 \\
(0-70.8)\end{array}$ & - & $3 / 6$ & $\begin{array}{c}50.00 \\
(11.8-80.6)\end{array}$ & - & - & - & - \\
\hline RDS (donor) & $0,1,0,0$ & - & - & - & $0 / 1$ & 0 & - & - & - & - & - & - & - \\
\hline
\end{tabular}

This article is protected by copyright. All rights reserved 


\begin{tabular}{|c|c|c|c|c|c|c|c|c|c|c|c|c|c|}
\hline 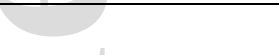 & & & & & & $(0-97.5)$ & & & & & & & \\
\hline RDS (recipient) & $0,1,0,0$ & - & - & - & $0 / 1$ & $\begin{array}{c}0 \\
(0-97.5)\end{array}$ & - & - & - & - & - & - & - \\
\hline $\begin{array}{c}\text { Admission to } \\
\text { NICU } \\
\text { (overall) }\end{array}$ & $2,1,3,0$ & $0 / 6$ & $\begin{array}{c}0 \\
(0-34.6)\end{array}$ & 0 & $0 / 3$ & $\begin{array}{c}0 \\
(0-70.8)\end{array}$ & - & $8 / 12$ & $\begin{array}{c}65.64 \\
(39.3-87.6)\end{array}$ & 0 & - & - & - \\
\hline $\begin{array}{l}\text { Admission to } \\
\text { NICU } \\
\text { (donor) }\end{array}$ & $2,1,2,0$ & $0 / 3$ & $\begin{array}{c}0 \\
(0-34.6)\end{array}$ & 0 & $0 / 1$ & $\begin{array}{c}0 \\
(0-97.5)\end{array}$ & - & $3 / 8$ & $\begin{array}{c}39.49 \\
(11.9-71.4)\end{array}$ & 0 & - & - & - \\
\hline \begin{tabular}{|c|} 
Admission to \\
NICU \\
(recipient) \\
\end{tabular} & $2,1,2,0$ & $0 / 3$ & $\begin{array}{c}0 \\
(0-34.6)\end{array}$ & 0 & $0 / 1$ & $\begin{array}{c}0 \\
(0-97.5)\end{array}$ & - & $3 / 8$ & $\begin{array}{c}39.49 \\
(11.9-71.4)\end{array}$ & 0 & - & - & - \\
\hline \multicolumn{14}{|c|}{ Intact survival } \\
\hline $\begin{array}{l}\text { Intact survival } \\
\text { (overall) }\end{array}$ & $0,1,2,0$ & - & - & - & $3 / 3$ & $\begin{array}{c}100 \\
(29 .-100)\end{array}$ & - & $12 / 23$ & $\begin{array}{c}51.89 \\
(32.3-71.2)\end{array}$ & 74.0 & - & - & - \\
\hline $\begin{array}{l}\text { Intact survival } \\
\text { (donor) }\end{array}$ & $0,0,2,0$ & - & - & - & $2 / 2$ & $\begin{array}{c}100 \\
(15.8-100)\end{array}$ & - & $5 / 11$ & $\begin{array}{c}33.10 \\
(0.1-89.0)\end{array}$ & 75.1 & - & - & - \\
\hline $\begin{array}{l}\text { Intact survival } \\
\text { (recipient) }\end{array}$ & $0,0,2,0$ & - & - & - & $1 / 1$ & $\begin{array}{c}100 \\
(2.5-100)\end{array}$ & - & $7 / 12$ & $\begin{array}{c}57.64 \\
(31.0-82.1)\end{array}$ & 0 & - & - & - \\
\hline
\end{tabular}

a: analysis not computed because the studies with information on the occurrence of IUD in the donor and recipient twin did not report any IUD. missing values are due to the fact that some fetuses underwent TOP.

IUD: intra-uterine death; NND: neonatal death; PND: perinatal death; PTB: preterm birth; RDS: respiratory distress syndrome; NICU: neonatal intensive care unit.

This article is protected by copyright. All rights reserved 
Table 4: Pooled proportions for the incidence of the different adverse outcomes explored in the present review in monochorionic diamniotic (MCDA) twin pregnancies complicated by early twin to twin transfusion syndrome occurring before 16 weeks of gestation.

\begin{tabular}{|c|c|c|c|c|c|c|c|c|c|c|c|c|c|}
\hline \multirow[b]{2}{*}{ Outcome } & \multirow[b]{2}{*}{ Studies (n) } & \multicolumn{3}{|c|}{ Expectant management } & \multicolumn{3}{|c|}{ Laser therapy } & \multicolumn{3}{|c|}{ Amnioreduction } & \multicolumn{3}{|c|}{ Cord occlusion } \\
\hline & & Fetuses (n) & $\begin{array}{c}\text { PP }(95 \% \\
\text { CI })\end{array}$ & $\mathrm{I}^{2}(\%)$ & $\begin{array}{c}\text { Fetuses } \\
\text { (n) }\end{array}$ & $\begin{array}{c}\text { PP }(95 \% \\
\text { CI })\end{array}$ & $I^{2}(\%)$ & Fetuses (n) & $\begin{array}{c}\text { PP }(95 \% \\
\text { CI })\end{array}$ & $\begin{array}{c}\mathbf{I}^{2}(\% \\
)\end{array}$ & $\begin{array}{c}\text { Fetuses } \\
\text { (n) }\end{array}$ & PP (95\% CI) & $I^{2}(\%)$ \\
\hline \multicolumn{14}{|c|}{ Mortality } \\
\hline IUD (overall) & $1,3,4,0$ & $0 / 2$ & $\begin{array}{c}0 \\
(0-84.2)\end{array}$ & - & $12 / 28$ & $\begin{array}{c}52.79 \\
(19.5-84.7)\end{array}$ & 67.4 & $1 / 16$ & $\begin{array}{c}11.10 \\
(1.2-29.2)\end{array}$ & 0 & - & - & - \\
\hline Single IUD & $1,3,4,0$ & $0 / 2$ & $\begin{array}{c}0 \\
(0-84.2)\end{array}$ & - & $4 / 28$ & $\begin{array}{c}24.21 \\
(0.4-679)\end{array}$ & 79.9 & $1 / 16$ & $\begin{array}{c}0 \\
(0-21.7)\end{array}$ & 0 & - & - & - \\
\hline Double IUD & $1,3,4,0$ & $0 / 2$ & $\begin{array}{c}0 \\
(0-84.2)\end{array}$ & - & $8 / 28$ & $\begin{array}{c}27.93 \\
(3.3-64.2)\end{array}$ & 70.3 & $1 / 16$ & $\begin{array}{c}11.10 \\
(1.2-29.2)\end{array}$ & 0 & - & - & - \\
\hline IUD donor & $1,2,4,0$ & $0 / 1$ & $\begin{array}{c}0 \\
(0-97.5)\end{array}$ & - & $6 / 13$ & $\begin{array}{c}46.49 \\
(22.0-71.9)\end{array}$ & 0 & $1 / 8$ & $\begin{array}{c}19.17 \\
(2.0-47.8 .7)\end{array}$ & 0 & - & - & - \\
\hline IUD recipient & $1,2,4$ & $0 / 1$ & $\begin{array}{c}0 \\
(0-97.5)\end{array}$ & - & $4 / 13$ & $\begin{array}{c}34.26 \\
(3.2-76.9)\end{array}$ & 63.8 & $0 / 8$ & $\begin{array}{c}0 \\
(0-32.7)\end{array}$ & 0 & - & - & - \\
\hline NND (overall) & $1,2,4,0$ & $0 / 2$ & $\begin{array}{c}0 \\
(0-84.2)\end{array}$ & - & $1 / 18$ & $\begin{array}{c}8.67 \\
(0.5-25.0)\end{array}$ & 0 & $2 / 16$ & $\begin{array}{c}12.55 \\
(1.7-31.2)\end{array}$ & 33.9 & - & - & - \\
\hline Single NND & $1,2,4,0$ & $0 / 2$ & $\begin{array}{c}0 \\
(0-84.2)\end{array}$ & - & $1 / 18$ & $\begin{array}{c}8.67 \\
(0.5-25.0)\end{array}$ & 0 & $0 / 16$ & $\begin{array}{c}0 \\
(0-19.3)\end{array}$ & 0 & - & - & - \\
\hline Double NND & $1,2,4,0$ & $0 / 2$ & $\begin{array}{c}0 \\
(0-84.2)\end{array}$ & - & $0 / 18$ & $\begin{array}{c}0 \\
(0-13.2)\end{array}$ & 0 & $2 / 16$ & $\begin{array}{c}12.55 \\
(1.7-31.2)\end{array}$ & 33.9 & - & - & - \\
\hline NND donor & $1,2,4,0$ & $0 / 1$ & 0 & - & $1 / 9$ & 16.03 & 0 & $1 / 8$ & 16.51 & 0 & - & - & - \\
\hline
\end{tabular}

This article is protected by copyright. All rights reserved 


\begin{tabular}{|c|c|c|c|c|c|c|c|c|c|c|c|c|c|}
\hline 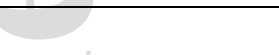 & & & $(0-97.5)$ & & & $(1.0-43.7)$ & & & $(1.2-44.3)$ & & & & \\
\hline NND (recipient) & $1,2,4,0$ & $0 / 1$ & $\begin{array}{c}0 \\
(0-97.5)\end{array}$ & - & $0 / 9$ & $\begin{array}{c}0 \\
(0-24.1)\end{array}$ & 0 & $1 / 8$ & $\begin{array}{c}16.51 \\
(1.2-44.3)\end{array}$ & 0 & - & - & - \\
\hline PND (overall) & $1,2,4,0$ & $0 / 2$ & $\begin{array}{c}0 \\
(0-84.2)\end{array}$ & - & $7 / 18$ & $\begin{array}{c}40.65 \\
(20.2-62.9)\end{array}$ & 73.4 & $3 / 16$ & $\begin{array}{c}21.16 \\
(6.0-42.4)\end{array}$ & 0 & - & - & - \\
\hline Single PND & $1,2,4,0$ & $0 / 2$ & $\begin{array}{c}0 \\
(0-84.2)\end{array}$ & - & $5 / 18$ & $\begin{array}{c}29.52 \\
(11.7-51.4)\end{array}$ & 81.7 & $1 / 16$ & $\begin{array}{c}11.10 \\
(1.2-29.2)\end{array}$ & 0 & - & - & - \\
\hline Double PND & $1,2,4,0$ & $0 / 2$ & $\begin{array}{c}0 \\
(0-84.2)\end{array}$ & - & $2 / 18$ & $\begin{array}{c}13.81 \\
(2.4-32.4)\end{array}$ & 0 & $2 / 16$ & $\begin{array}{c}13.94 \\
(0.7-40.0)\end{array}$ & 33.9 & - & - & - \\
\hline PND donor & $1,1,4,0$ & $0 / 1$ & $\begin{array}{c}0 \\
(0-97.5)\end{array}$ & $0 / 1$ & $4 / 8$ & $\begin{array}{c}50.00 \\
(15.7-84.3)\end{array}$ & - & $2 / 8$ & $\begin{array}{c}17.01 \\
(3.7-37.2)\end{array}$ & 0 & - & - & - \\
\hline PND recipient & $1,1,4,0$ & $0 / 1$ & $\begin{array}{c}0 \\
(0-97.5)\end{array}$ & $0 / 1$ & $1 / 8$ & $\begin{array}{c}12.50 \\
(0.3-82.7)\end{array}$ & - & $1 / 8$ & $\begin{array}{c}9.26 \\
(0.6-26.5)\end{array}$ & 0 & - & - & - \\
\hline & & & & & & & & & & & & & \\
\hline PTB <32 weeks & $1,3,4,0$ & $1 / 1$ & $\begin{array}{c}100 \\
(25.0-100) \\
\end{array}$ & 0 & $9 / 14$ & $\begin{array}{c}63.13 \\
(38.5-84.6) \\
\end{array}$ & 0 & $3 / 8$ & $\begin{array}{c}40.55 \\
(13.8-70.8) \\
\end{array}$ & 0 & - & - & - \\
\hline$a^{2}$ & & & & & & & & & & & & & \\
\hline 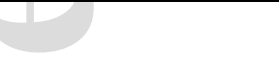 & & & & & & Morbidity & & & & & & & \\
\hline $\begin{array}{c}\text { Composite } \\
\text { morbidity } \\
\text { (overall) }\end{array}$ & $1,0,2,0$ & $0 / 2$ & $\begin{array}{c}0 \\
(0-84.2)\end{array}$ & - & - & - & - & $3 / 6$ & $\begin{array}{c}50.48 \\
(18.9-86.2)\end{array}$ & 67.2 & - & - & - \\
\hline $\begin{array}{l}\text { Composite } \\
\text { morbidity }\end{array}$ & $1,0,2,0$ & $0 / 1$ & $\begin{array}{c}0 \\
(0-97.5)\end{array}$ & $0 / 1$ & - & - & - & $2 / 3$ & $\begin{array}{c}64.51 \\
(18.3-97.8)\end{array}$ & 0 & - & - & - \\
\hline
\end{tabular}

This article is protected by copyright. All rights reserved 


\begin{tabular}{|c|c|c|c|c|c|c|c|c|c|c|c|c|c|}
\hline (donor) & & & & & & & & & & & & & \\
\hline $\begin{array}{l}\text { Composite } \\
\text { morbidity } \\
\text { (recipient) }\end{array}$ & $1,0,120$ & $0 / 1$ & $\begin{array}{c}0 \\
(0-97.5)\end{array}$ & $0 / 1$ & - & - & - & $1 / 3$ & $\begin{array}{c}35.49 \\
(2.2-81.7)\end{array}$ & 0 & - & - & - \\
\hline ) & & & & & & & & & & & & & \\
\hline $\begin{array}{c}\text { Neuromorbidity } \\
\text { (overall) }\end{array}$ & $1,0,0,0$ & $0 / 2$ & $\begin{array}{c}0 \\
(0-84.2)\end{array}$ & - & - & - & - & - & - & - & - & - & - \\
\hline $\begin{array}{l}\text { Neuromorbidity } \\
\text { (donor) }\end{array}$ & $1,0,0,0$ & $0 / 1$ & $\begin{array}{c}0 \\
(0-97.5)\end{array}$ & $0 / 1$ & - & - & - & - & - & - & - & - & - \\
\hline $\begin{array}{c}\text { Neuromorbidity } \\
\text { (recipient) }\end{array}$ & $1,0,0,0$ & $0 / 1$ & $\begin{array}{c}0 \\
(0-97.5)\end{array}$ & $0 / 1$ & - & - & - & - & - & - & - & - & - \\
\hline 1 & & & & & & & & & & & & & \\
\hline $\begin{array}{c}\text { Severe } \\
\text { neuromorbidity } \\
\text { (overall) }\end{array}$ & $1,0,0,0$ & $0 / 2$ & $\begin{array}{c}0 \\
(0-84.2)\end{array}$ & - & - & - & - & - & - & - & - & - & - \\
\hline $\begin{array}{c}\text { Severe } \\
\text { neuromorbidity } \\
\text { (recipient) }\end{array}$ & $1,0,0,0$ & $0 / 1$ & $\begin{array}{c}0 \\
(0-97.5)\end{array}$ & $0 / 1$ & - & - & - & - & - & - & - & - & - \\
\hline 7 & & & & & & & & & & & & & \\
\hline RDS (overall) & $0,0,0,0$ & - & - & - & - & - & - & - & - & - & - & - & - \\
\hline RDS (donor) & $0,0,0,0$ & - & - & - & - & - & - & - & - & - & - & - & - \\
\hline RDS (recipient) & $0,0,0,0$ & - & - & - & - & - & - & - & - & - & - & - & - \\
\hline
\end{tabular}

This article is protected by copyright. All rights reserved 


\begin{tabular}{|c|c|c|c|c|c|c|c|c|c|c|c|c|c|}
\hline \multirow{2}{*}{\multicolumn{14}{|c|}{ 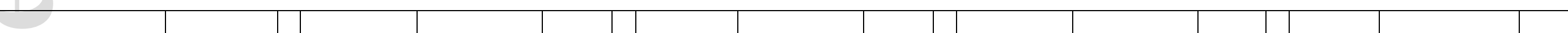 }} \\
\hline & & & & & & & & & & & & & \\
\hline $\begin{array}{l}\text { Admission to } \\
\text { NICU } \\
\text { (overall) }\end{array}$ & $1,0,1,0$ & $0 / 2$ & $\begin{array}{c}0 \\
(0-84.2)\end{array}$ & $0 / 1$ & - & - & - & $2 / 2$ & $\begin{array}{c}100 \\
(15.8-100)\end{array}$ & - & - & - & - \\
\hline $\begin{array}{c}\text { Admission to } \\
\text { NICU } \\
\text { (donor) }\end{array}$ & $1,0,1,0$ & $0 / 1$ & $\begin{array}{c}0 \\
(0-97.5)\end{array}$ & $0 / 1$ & - & - & - & $1 / 1$ & $\begin{array}{c}100 \\
(25.0-100)\end{array}$ & - & - & - & - \\
\hline $\begin{array}{l}\text { Admission to } \\
\text { NICU } \\
\text { (recipient) }\end{array}$ & $1,0,1,0$ & $0 / 1$ & $\begin{array}{c}0 \\
(0-97.5)\end{array}$ & $0 / 1$ & - & - & - & $1 / 1$ & $\begin{array}{c}100 \\
(25.0-100)\end{array}$ & - & - & - & - \\
\hline \multicolumn{14}{|c|}{ Intact survival } \\
\hline $\begin{array}{c}\text { Intact survival } \\
\text { (overall) }\end{array}$ & $0,0,2,0$ & - & - & - & - & - & - & $6 / 10$ & $\begin{array}{c}56.54 \\
(11.2-95.6)\end{array}$ & 65.3 & - & - & - \\
\hline $\begin{array}{c}\text { Intact survival } \\
\text { (donor) }\end{array}$ & $0,0,2,0$ & - & - & - & - & - & - & $2 / 5$ & $\begin{array}{c}35.23 \\
(0.2-88.8)\end{array}$ & 53.7 & - & - & - \\
\hline $\begin{array}{c}\text { Intact survival } \\
\text { (recipient) }\end{array}$ & $0,0,2,0$ & - & - & - & - & - & - & $4 / 5$ & $\begin{array}{c}77.32 \\
(28.6-99.9)\end{array}$ & 37.5 & - & - & - \\
\hline
\end{tabular}

Missing values are due to the fact that some fetuses underwent TOP.

IUD: intra-uterine death; NND: neonatal death; PND: perinatal death; PTB: preterm birth; RDS: respiratory distress syndrome; NICU: neonatal intensive care unit.

This article is protected by copyright. All rights reserved 


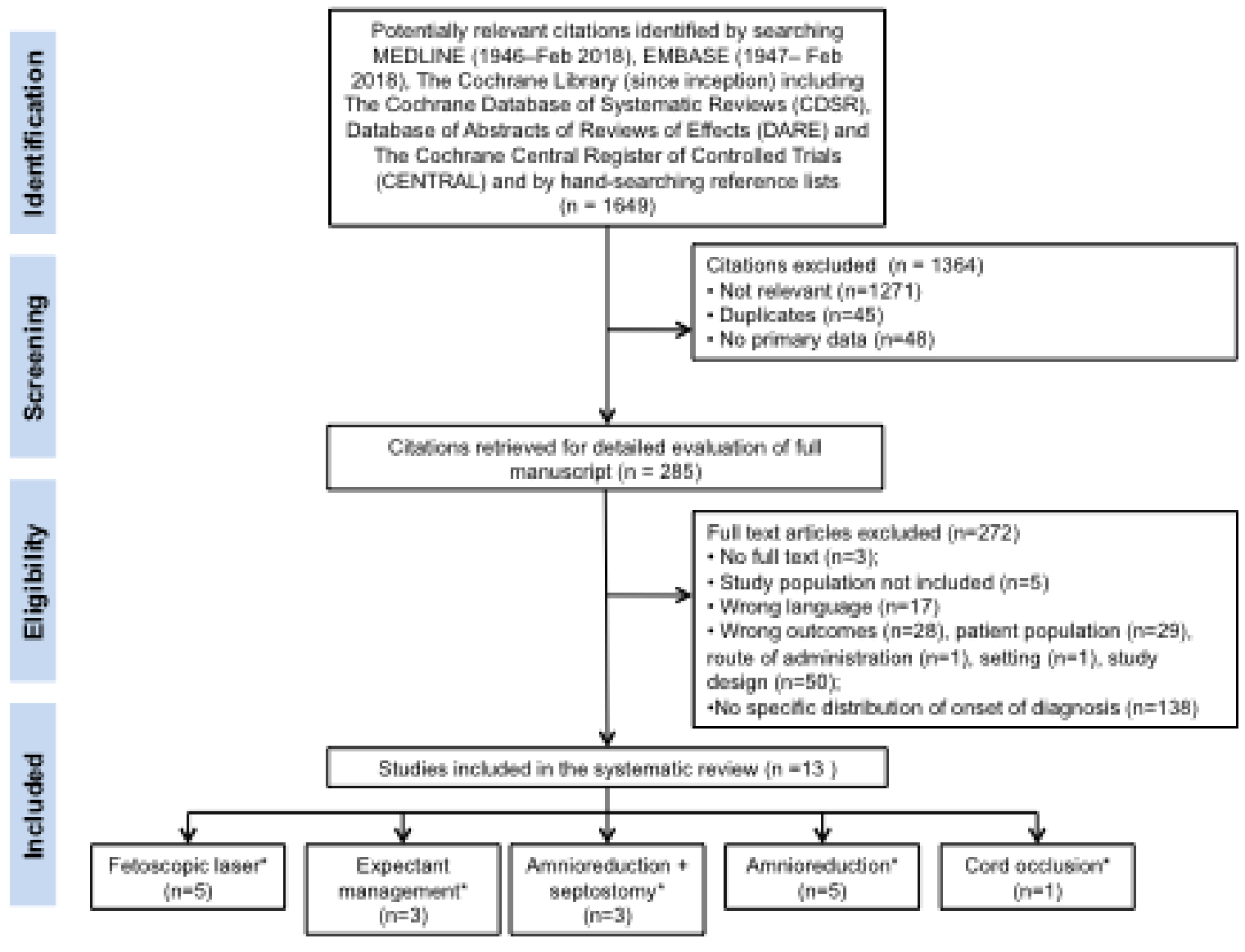

aogs_13840_f1.png 
